\title{
EDITORIAL
}

\section{The European Union conference on chronic respiratory disease: purpose and conclusions}

\author{
M. Decramer*, Y. Sibille" ${ }^{\#}$ A. Bush ${ }^{\ddagger}$, K-H. Carlsen ${ }^{+}$, K.F. Rabe ${ }^{\S}$, L. Clancy ${ }^{\dagger}$, A. Turnbull**, B. Nemery ${ }^{\# \#, ~}$ \\ A. Simonds ${ }^{\pi /}$ and T. Troosters ${ }^{++}$
}

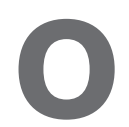

n October 19, 2010, the European Respiratory Society (ERS) organised, at the request of the Belgian presidency of the Council of the European Union, the first ever pre-ministerial conference on "Chronic respiratory disease - exploring solutions in the EU". On October 20, the conclusions of this conference were presented to the conference of the ministers of health and the top policy makers of the 27 EU countries, under the presidency of L. Onkelinkx, the Belgian Health Minister. Finally, several elements of these conclusions were incorporated in European Council conclusions on chronic disease [1]. This pre-ministerial conference was the first ever high level conference on chronic respiratory disease and it was a worthwhile milestone in the "Year of the Lung" effort proclaimed by the Forum of International Respiratory Societies (www.yearofthelung.org).

The main themes of the conference were prevention and care of respiratory disease, patient empowerment and innovative models of care. There was active participation of patients and patient organisations (i.e. EFA, the European Federation of Allergy and Airway Disease Patients). Patient empowerment was defined as continuous education for patients, equal access to treatment and a meaningful involvement of patients in the decision making process. The importance of chronic respiratory disease cannot be overestimated. The big five respiratory disorders (chronic obstructive pulmonary disease, COPD, asthma, lung cancer, pneumonia and tuberculosis, are responsible for $20 \%$ of mortality worldwide $[2,3]$. The cost of treating these diseases in Europe is $€ 100$ billion annually. COPD affects 210 million people in the world, according to a recent estimation of the World Health Organization (WHO), and 44 million people in Europe [4]. It is presently the fourth leading cause of death and it will become the third leading cause of death by 2030. It is currently the first leading cause of healthcare expenditure in the EU. While the mortality due to cardiovascular disease and stroke has been decreasing, the

\footnotetext{
*Respiratory Division, University of Leuven, Leuven, Belgium. ${ }^{*}$ Respiratory Division, University of Louvain, Louvain-la-Neuve, Belgium. "Paediatric Respirology, Imperial College London, London, UK. ${ }^{+}$Dept of Paediatrics, Oslo University Hospital, University of Oslo and Norwegian School of Sport Sciences, Oslo, Norway. ${ }^{\S}$ University of Kiel, Kiel and Grosshansdorf Hospital, Germany. ${ }^{{ }^{\top}}$ TobaccoFree Research Institute, Dublin, Ireland. ${ }^{* *}$ European Respiratory Society and European Public Health Alliance, Lausanne, Switzerland. ${ }^{\# \#}$ Dept of Public Health, University of Leuven, Louvain, Belgium. "Academic Unit of Sleep and Breathing, Royal Brompton and Harefield NHS Foundation Trust, London, UK. ${ }^{++}$Respiratory Rehabilitation, University of Leuven, Leuven, Belgium.

CORRESPONDENCE: M. Decramer, Chief Respiratory Division, University Hospital, Herestraat 49, 3000 Leuven, Belgium. E-mail: Marc.Decramer@uzleuven.be
}

mortality due to COPD has been increasing during the past three decades (fig. 1), indicating that COPD in particular, and chronic respiratory disease in general, will become the diseases of the next decades [5]. The impact of COPD on disabilityadjusted life years is also increasing. In this context, it is surprising that proportionally limited funds are committed to research on chronic respiratory disease, apart from some visionary exceptions. Indeed, for example in the UK in 2002, only $2.8 \%$ of the Medical Research Council budget was claimed by respiratory disease, whereas respiratory diseases were responsible for $13 \%$ of the causes of mortality [6].

COPD will thus pose a tremendous problem in the next decade, also in view of the ageing of the population. The disease is still often underestimated by both patients and physicians $[7,8]$. It is associated with multiple comorbidities, such as muscle weakness, osteoporosis, diabetes, cardiovascular disease, hypertension, depression and lung cancer [9]. This will necessitate new modes of approach to this chronic disease, such as integrated and multidisciplinary care, clinical pathways, self management [10], teleconsulting, telemonitoring [11] and rehabilitation [12]. For the latter four modalities there is evidence of an effect on outcomes, but accessibility of these services remains dismal. It is estimated that less than $5 \%$ of the eligible patients currently have access to rehabilitation [13]. Telemedicine is not adopted by most healthcare systems and, hence, is not truly making its way to healthcare delivery beyond the "pilot stage" [14]. Moreover, more research is required into the pathogenesis of COPD in order to ensure the development of effective disease modifying therapy in the future. Lung cancer remains the number one cancer killer and its importance will increase in the next decades [2].

Chronic respiratory disease starts in childhood, and even in utero, when the lung of the fetus and the child is very vulnerable to environmental factors such as cigarette smoke and air pollution. This was highlighted by pivotal epidemiological studies showing that there was a close and positive relationship over a wide variety of geographical locations between infant mortality from bronchitis and pneumonia and adult mortality from bronchitis 50 yrs later [15]. The major adverse effects are from tobacco smoking. This causes structural changes such as increased airway smooth muscle and wall thickness, reduced alveolar tethering points and increased lung collagen deposition [16,17]. Tobacco smoke has a trans-generational effect on respiratory risk by epigenetic mechanisms; if the grandmother has smoked in pregnancy, her 

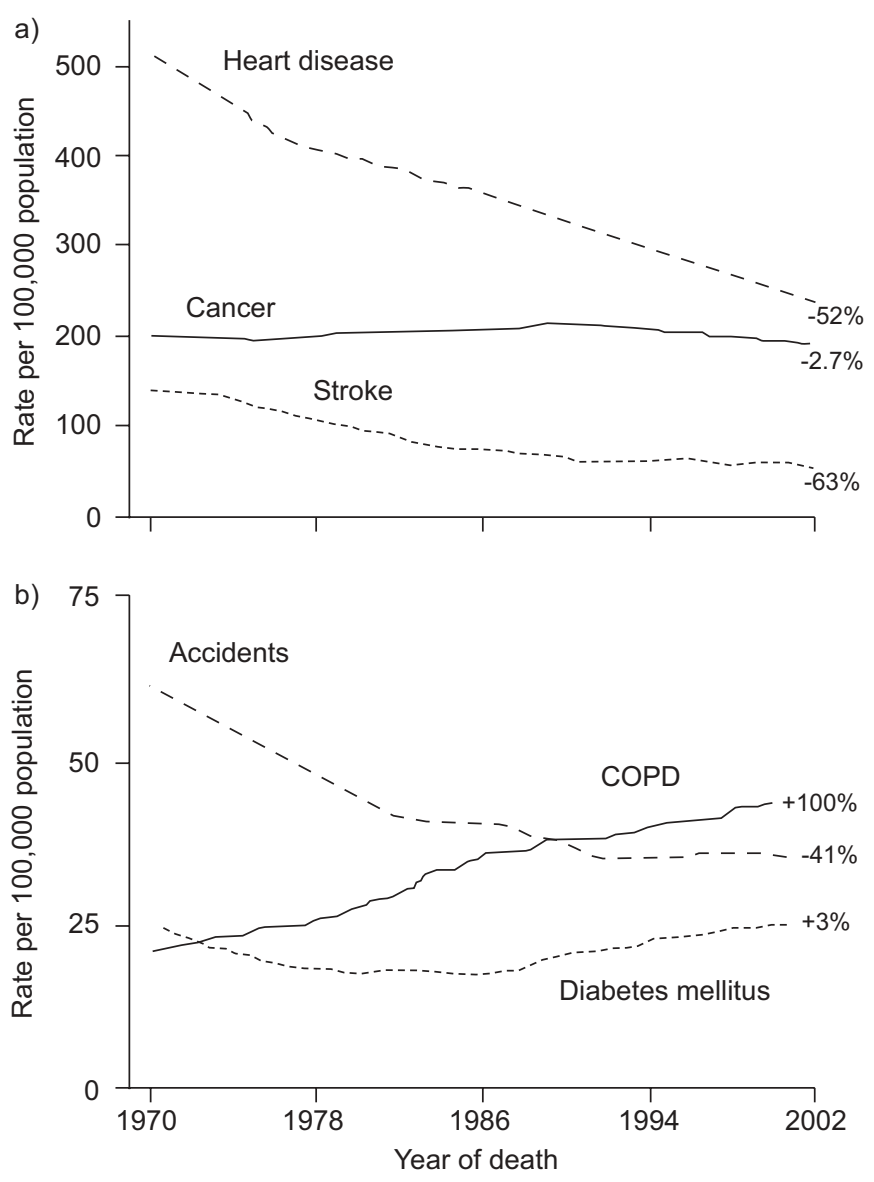

FIGURE 1. Evolution of mortality due to various diseases over the past $30 \mathrm{yrs}$. COPD: chronic obstructive pulmonary disease. Reproduced and modified from [5] with permission from the publisher.

daughter's children have an increased risk of asthma even if her daughter herself did not smoke [18]. Epigenetic changes in the CD14 gene (cluster differentiation gene), which are induced by exposure to secondhand smoke or environmental pollution and consist of methylation of the CD14 gene, are linked to the development of asthma [19].

Exposure of the pregnant mother to pollution (e.g. to particulate matter or nitrogen dioxide) has adverse effects on the unborn baby [20]. Postnatally, tobacco smoke exposure continues to be an important adverse factor, as does pollution $[21,22]$. Postnatally, lung function increases to a plateau at age 20-25 yrs, and subsequently declines. The normal plateau will not be reached if the baby starts with low lung function, or there is impaired development of the airways in childhood. Numerous studies have shown that lung function tracks, and there is no catch-up growth after 4 yrs of age [23-26]. An accelerated rate of decline in lung function from the plateau is a risk factor for COPD. This is seen in active smokers, but also in those who had recurrent episodic wheeze in early childhood [27]. The Melbourne asthma study, which has followed children from age 7 to $50 \mathrm{yrs}$, has demonstrated that lung function tracks throughout this period; that nearly $50 \%$ of childhood severe asthmatics develop COPD by age $50 \mathrm{yrs}$; and that those adults who develop COPD have the lowest childhood lung function when tracked back over the decades [28]. Another study showed that childhood disadvantage (defined by five factors, maternal, paternal or childhood asthma, maternal smoking and childhood respiratory infection) was associated with lower lung function with no catch-up growth, a faster rate of decline in lung function, and a greater risk of COPD [29]. In both these studies, childhood adverse events had at least as great an effect on COPD as adult life smoking [28, 29]. Thus, public health measures in pregnancy and early life offer the opportunity to improve lung health. The ban on smoking in public places in Scotland led to an 18\% reduction of asthma admissions in children aged below 15 yrs [30]. Most importantly, research should be directed at how best to protect the developing lung, so children go into adult life and old age in optimal respiratory health.

The increasing prevalence of asthma that is observed in later childhood and shown to increase further from childhood, through adolescence and into adulthood, demonstrates a potential for an even more increasing prevalence of chronic respiratory disease in adulthood [31]. The lifetime risk for asthma increases from early life and continues to do so until the age of $80 \mathrm{yrs}$. This early start makes this a lifelong disease with important consequences for quality of life, personal economy and health economy, when compared to other chronic disorders that start later in life (fig. 2) [31]. Young athletes often develop asthma and bronchial hyperresponsiveness, as asthma symptoms were recently demonstrated in $83 \%$ of adolescent competitive swimmers and bronchial hyperresponsiveness in $71 \%$ [32]. This may also have dramatic consequences. In a survey of athletic deaths, 55 out of 263 deaths were due to asthma, with the highest occurrence in adolescence and with a lack of asthma controlling therapy in almost all of these athletes [33]. Multidisciplinary treatment with a focus on lifestyle as physical activity, nutrition and avoidance of smoking has improved the quality of life and life expectancy in children and adolescents with chronic respiratory disorders such as cystic fibrosis and primary ciliary dyskinesia. Early diagnosis and treatment is of the utmost importance for later life in these patients.

Infections still play a very important role in the older age category. Community-acquired pneumonia (CAP) remains a serious problem in adults and in the elderly [34]. In particular, the very high rates of antibiotic resistance are preoccupying [35]. Moreover, tuberculosis cannot be viewed as a solved problem as it remains one of the prime global problems, causing about 1.7 million deaths each year [36]. Surprisingly, its prevalence remains high in certain European countries and the problem of urban tuberculosis poses a problem to most European major cities [37]. In the countries where the prevalence is relatively low, the success rate of anti-tuberculous treatment is generally below $85 \%$ [38].

The respiratory tract is a primary target of injury caused by exposure to air pollution. Tobacco smoking is, of course, a dramatically potent way of exposing oneself ("do-it-yourself air pollution") and others to potent irritants, toxic and carcinogenic agents. In the home too, various types of air pollutants have been recently shown to cause or precipitate respiratory disease. Thus, burning biomass for cooking and heating is an important cause of COPD in females from poor 

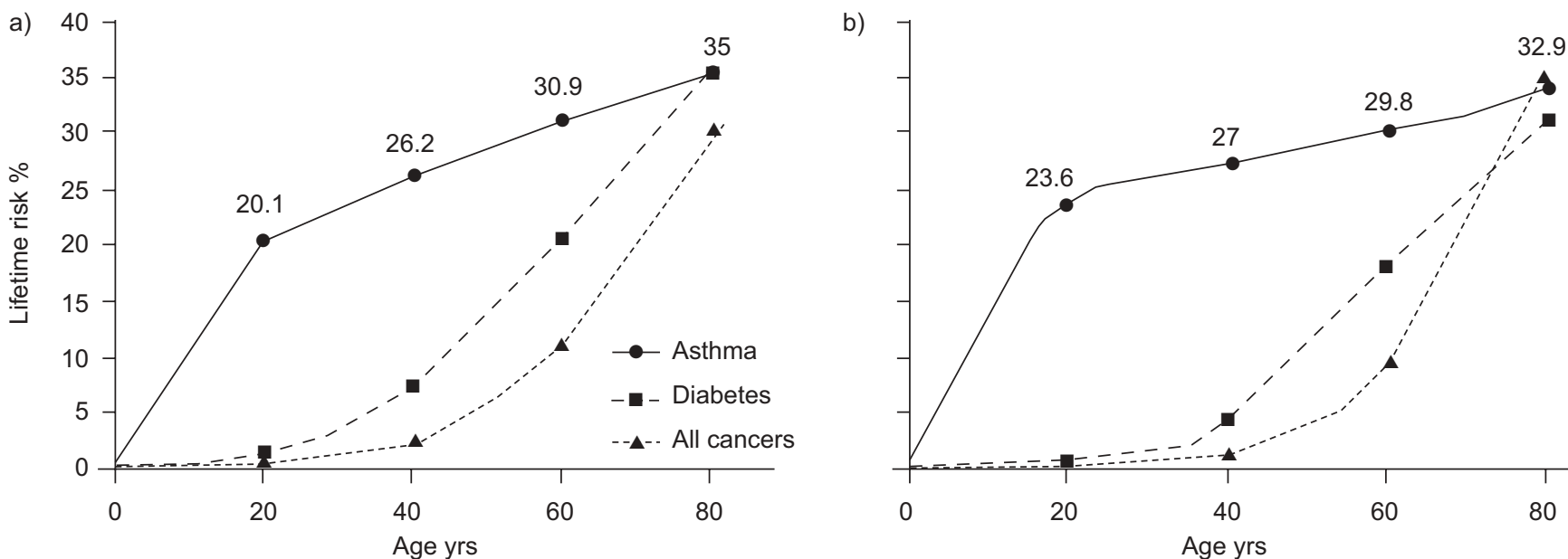

FIGURE 2. Lifetime risk of asthma, diabetes and malignancy in a) females and b) males. Reproduced and modified from [31] with permission from the publisher.

countries [39], and frequent use of (sprayed) cleaning products increases the risk of asthma in adults [40] and children [41]. Even in economically advanced countries, occupational exposures to gases and vapours, mineral and organic dusts, or infectious agents still constitute substantial risks of both specific and nonspecific lung disease [42]. Thus, it has been estimated that occupational exposures contribute to $15 \%$ of cases of asthma or COPD in industrial countries [43-45]. Occupational exposures, especially to asbestos, also contribute to lung cancer [46]. Finally, outdoor air pollution caused by industrial emissions and vehicle traffic is also a significant cause of respiratory, as well as cardiovascular, morbidity and mortality in children and adults [47].

A more aggressive approach to reducing the known risk factors is required for effective prevention of chronic respiratory disease. The recent Eurobarometer survey on smoking shows an alarming prevalence of smoking in the EU, with only Portugal, Sweden and the Netherlands reaching a reasonably low prevalence $(15-20 \%)$ and with some of the southern European countries (e.g. Spain and Greece) still having a prevalence exceeding $35 \%$ [48]. This occurs despite the active policy of the EU Commission, Council and Parliament in this area. Smoking should be regarded as a disease and the measures of the WHO Framework Convention for Tobacco Control (FCTC) should be fully implemented [49]. An example is the fact that considerably more effort should be put into cessation programmes if there is to be any prospect of preventing the predicted rise in chronic respiratory diseases [50]. These programmes are cheap and highly cost-effective especially in the context of chronic respiratory diseases [51]. In this regard, the recent Conference of the Parties (COP4) to the WHO FCTC decided to issue excellent guidelines on how the parties could encourage smoking cessation, ranging from making the recording of tobacco use in medical notes mandatory to the development and dissemination of comprehensive guidelines and addressing tobacco use by healthcare workers and others involved in smoking cessation [52].

There has been great progress in the extension of smoke free laws in the EU since Ireland, in 2004, was the first country in the world to become smoke free, with immediate improvement in indoor air and respiratory health [53], but the burden of disease from secondhand smoke remains a very significant problem and protection from passive smoking should be addressed more vigorously [54]. There is no safe level of exposure to secondhand smoke. Worldwide, $40 \%$ of children, $33 \%$ of male nonsmokers and $35 \%$ of female nonsmokers were exposed to secondhand smoke in 2004, which caused an estimated 603,000 deaths each year among nonsmokers [54]. An estimated 250,300 of these deaths are due to chronic respiratory diseases. The burden of death and disease caused by secondhand smoke is greatest among females and children. These facts should be taken into account as the European Commission considers the possible revision of the Tobacco Products Directive. There is also a great need to continue to reduce air pollution exposure. Sources of air pollution, whether in the home, at work or in the ambient environment, should be reduced and existing exposure standards should at least be respected [47]. Where necessary, these standards should be revised to provide a maximal protection of the most vulnerable sections of the population [55]. Reductions in air pollution, whether implemented through regulation or otherwise, have been demonstrated to be beneficial in terms of gains in life expectancy $[47,55,56]$.

The newly emerging risk factors like inactivity and obesity should also be addressed. Their interaction with smoking behaviour should be clarified. Inactivity may amplify the devastating effects of smoking [57] and may lead to obesity, type II diabetes and osteoporosis. These comorbidities are typically associated with COPD [9]. Early signs and symptoms of COPD also lead to inactivity, as symptoms of respiratory diseases typically aggravate with exercise, leading to physical activity avoidance. Activity promoting programmes should consist of primary preventive programmes for the healthy, and specifically tailored secondary preventive programmes for patients with chronic respiratory disease [58]. New programmes do not necessarily need to be exceedingly expensive and can be implemented in the community, particularly in those with mild to moderate disease [59]. The example of the successful asthma control programme in Finland illustrates that a lot can be achieved with existing resources if these are better organised and coordinated [60]. Obesity in Europe has 
reached epidemic proportions [61] and is a major risk factor for obstructive sleep apnoea (OSA). It is estimated that OSA affects around 5 million people in Europe but, of those, that only 1 million are receiving treatment. This is a disturbing finding as OSA is associated with increased risk of road traffic accidents, and a higher incidence of hypertension [62] and vascular events. While weight loss may be sufficient and dental splints may help some individuals, in those with moderate or severe OSA, nasal continuous positive airway pressure therapy not only provides prompt symptomatic relief, but effectively reduces road traffic accidents and vascular risk [63]. In addition to tackling obesity, sleep study diagnostic and treatment facilities should be increased to manage this remediable problem.

For all these reasons, ERS decided to use its scientific, professional and educational potential to develop a roadmap of respiratory disease to provide guidance to the health policy makers on which action needs to be taken to deal with the problem of chronic respiratory disease in the next two decades. ERS has set up a mechanism whereby all Assemblies, the Scientific Committee, the School, the Tobacco Control Committee, the Environment Committee and all other relevant committees and, last but not least, all of its more than 11,500 members will provide input to the final document. This document will be further developed and put into perspective with other disease areas and with general aspects of our European societies, such as the evolution of the economy and healthcare, research, education and the burden of disease. It will finally be launched at the next ERS Congress in Amsterdam in September 2011. We sincerely hope that these efforts will bear fruit and eventually contribute to better ways to deal with the epidemic of chronic respiratory disease we are presently confronted with. ERS will continue to organise and lead such events in the future, as public awareness has become critically important for adequate financial support for prevention, care, education and research in disease [64].

\section{STATEMENT OF INTEREST}

Statements of interest for M. Decramer, L. Clancy and A. Simonds can be found at www.erj.ersjournals.com/site/misc/statements.xhtml

\section{ACKNOWLEDGEMENTS}

M. Decramer is President, Y. Sibille is EU Secretary, K.F. Rabe is President-Elect, A. Turnbull is Executive Director, A. Simonds is School Chair-Elect and L. Clancy is Chairman of the Tobacco Control Committee of the European Respiratory Society.

\section{REFERENCES}

1 Employment, Social Policy, Health and Consumer Affairs Council meeting, Brussels 7 December 2010. Council Conclusions: Innovative approaches for chronic disease in public health and health care systems. www.ersnet.org/images/Stories/CouncilConclusions_ Innovative_approaches_for_chronic_disease_in_public_health_and_ healthcare_systems_07DEC2010.pdf Date last accessed: January 24, 2011

2 Chronic Disease Alliance. A Unified Prevention Approach. European Society of Cardiology, European Society of Hypertension, European Cancer Organisation, European Association for the Study of the Liver, International Diabetes Federation (Europe), European Heart Network, European Respiratory Society, European Society for Medical Oncology, European Kidney Health Alliance, Foundation of European
Nurses in Diabetes, 2010. Available from: www.escardio.org/about/ what/advocacy/Documents/Chronic-disease-alliance-final.pdf

3 Loddenkemper R, Gibson GJ, Sibille Y, eds. European Lung White Book: the First Comprehensive Survey on Respiratory Health in Europe. Sheffield, European Respiratory Society/European Lung Foundation, 2003; pp. 16-23.

4 World Health Organization. World Health Statistics 2008. Geneva, World Health Organization, 2008. Available from: www.who.int/ whosis/whostat/EN_WHS08_Full.pdf

5 Jemal A, Ward E, Hao Y, et al. Trends in the leading causes of death in the United States, 1970-2002. JAMA 2005; 294: 1255-1259.

6 Laurent GJ. Getting grant applications funded: lessons from the past and advice for the future. Thorax 2004; 59: 1010-1011.

7 Rennard S, Decramer M, Calverley PM, et al. Impact of COPD in North America and Europe in 2000: subjects' perspective of Confronting COPD International Survey. Eur Respir J 2002; 20: 799-805.

8 Soriano JB, Zielinski J, Price D. Screening for and early detection of chronic obstructive pulmonary disease. Lancet 2009; 374: 721-732.

9 Decramer M, Rennard S, Troosters T, et al. COPD as a lung disease with systemic consequences - clinical impact, mechanisms, and potential for early intervention. COPD 2008; 5: 235-256.

10 Bourbeau J, Julien M, Maltais F, et al. Reduction of hospital utilization in patients with chronic obstructive pulmonary disease: a disease-specific self-management intervention. Arch Intern Med 2003; 163: 585-591.

11 Casas A, Troosters T, Garcia-Aymerich J, et al. Integrated care prevents hospitalisations for exacerbations in COPD patients. Eur Respir J 2006; 28: 123-130.

12 Troosters T, Casaburi R, Gosselink R, et al. Pulmonary rehabilitation in chronic obstructive pulmonary disease. Am J Respir Crit Care Med 2005; 172: 19-38.

13 Brooks D, Sottana R, Bell B, et al. Characterization of pulmonary rehabilitation programs in Canada in 2005. Can Respir J 2007; 14: 87-92.

14 Harvey S, Peterkin G, Wootton R. Eleven years of experience with low-bandwidth telemedicine in a nurse-led rural clinic in Scotland. J Telemed Telecare 2010; 16: 417-421.

15 Barker D, ed. Fetal and Infant Origins of Adult Disease. London, BMJ Books, 1992.

16 Elliot J, Vullermin P, Robinson P. Maternal cigarette smoking is associated with increased inner airway wall thickness in children who die from sudden infant death syndrome. Am J Respir Crit Care Med 1998; 158: 802-806.

17 Elliot J, Vullermin P, Carroll N, et al. Increased airway smooth muscle in sudden infant death syndrome. Am J Respir Crit Care Med 1999; 160: 313-316.

18 Li YF, Langholz B, Salam MT, et al. Maternal and grandmaternal smoking patterns are associated with early childhood asthma. Chest 2005; 127: 1232-1241.

19 Munthe-Kaas MC, Torjussen TM, Gervin K, et al. CD14 polymorphisms and serum CD14 levels through childhood: a role for gene methylation? J Allergy Clin Immunol 2010; 125: 1361-1368.

20 Latzin P, Roosli M, Huss A, et al. Air pollution during pregnancy and lung function in newborns: a birth cohort study. Eur Respir J 2009; 33: 594-603.

21 Kulkarni N, Pierse N, Rushton L, et al. Carbon in airway macrophages and lung function in children. N Engl J Med 2006; 355: 21-30.

22 Rojas-Martinez R, Perez-Padilla R, Olaiz-Fernandez G, et al. Lung function growth in children with long-term exposure to air pollutants in Mexico City. Am J Respir Crit Care Med 2007; 176: 377-384.

23 Sears MR, Greene JM, Willan AR, et al. A longitudinal, populationbased, cohort study of childhood asthma followed to adulthood. N Engl J Med 2003; 349: 1414-1422. 
24 Morgan WJ, Stern DA, Sherrill DL, et al. Outcome of asthma and wheezing in the first 6 years of life: follow-up through adolescence. Am J Respir Crit Care Med 2005; 172: 1253-1258.

25 Turner SW, Palmer LJ, Rye PJ, et al. The relationship between infant airway function, childhood airway responsiveness, and asthma. Am J Respir Crit Care Med 2004; 169: 921-927.

26 Oswald H, Phelan PD, Lanigan A, et al. Childhood asthma and lung function in mid-adult life. Pediatr Pulmonol 1997; 23: 14-20.

27 Edwards CA, Osman LM, Godden DJ, et al. Wheezy bronchitis in childhood: a distinct clinical entity with lifelong significance? Chest 2003; 124: 18-24.

28 Tran H, Tai A, Roberts M. COPD: an outcome of childhood asthma? Eur Respir J 2010; 36: 1016s.

29 Svanes C, Sunyer J, Plana E, et al. Early life origins of chronic obstructive pulmonary disease. Thorax 2010; 65: 14-20.

30 Mackay D, Haw S, Ayres JG, et al. Smoke-free legislation and hospitalizations for childhood asthma. N Engl J Med 2010; 363: $1139-1145$

31 To T, Wang C, Guan J, et al. What is the lifetime risk of physiciandiagnosed asthma in Ontario, Canada? Am J Respir Crit Care Med 2010; 181: 337-343.

32 Stadelmann K, Stensrud T, Carlsen KH. Respiratory symptoms and bronchial responsiveness in competitive swimmers. Med Sci Sports Exerc 2010; [Epub ahead of print].

33 Becker JM, Rogers J, Rossini G, et al. Asthma deaths during sports: report of a 7-year experience. J Allergy Clin Immunol 2004; 113: 264-267.

34 Fedson D, Musher D. Pneumococcal polysaccharide vaccine. In: Plotkin S, Orenstein W, eds. Vaccines. Philadelphia, Saunders W, 2004; pp. 529-587.

35 Riedel S, Beekmann SE, Heilmann KP, et al. Antimicrobial use in Europe and antimicrobial resistance in Streptococcus pneumoniae. Eur J Clin Microbiol Infect Dis 2007; 26: 485-490.

36 World Health Organization. Global Tuberculosis Control 2009. Epidemiology, Strategy, Financing. Geneva, World Health Organization, 2009. Available from: www.who.int/tb/publications/ global_report/2009/en/

37 Landesman SH. Commentary: tuberculosis in New York City - the consequences and lessons of failure. Am J Public Health 1993; 83: 766-768.

38 European Antimicrobial Resistance Surveillance System. EARSS: Annual Report 2008. Bilthoven, National Institute for Public Health and the Environment, 2008. Available from: www.ecdc. europa.eu/en/activities/surveillance/EARS-Net/Documents/2008_ EARRS_Annual_Report.pdf

39 Salvi SS, Barnes PJ. Chronic obstructive pulmonary disease in nonsmokers. Lancet 2009; 374: 733-743.

40 Zock JP, Plana E, Jarvis D, et al. The use of household cleaning sprays and adult asthma: an international longitudinal study. Am J Respir Crit Care Med 2007; 176: 735-741.

41 Sherriff A, Farrow A, Golding J, et al. Frequent use of chemical household products is associated with persistent wheezing in preschool age children. Thorax 2005; 60: 45-49.

42 Sigsgaard T, Nowak D, Annesi-Maesano I, et al. ERS position paper: work-related respiratory diseases in the EU. Eur Respir J 2010; 35: 234-238.

43 Balmes J, Becklake M, Blanc P, et al. American Thoracic Society Statement: occupational contribution to the burden of airway disease. Am J Respir Crit Care Med 2003; 167: 787-797.

44 Blanc PD, Iribarren C, Trupin L, et al. Occupational exposures and the risk of COPD: dusty trades revisited. Thorax 2009; 64: 6-12.
45 Kogevinas M, Zock JP, Jarvis D, et al. Exposure to substances in the workplace and new-onset asthma: an international prospective population-based study (ECRHS-II). Lancet 2007; 370: 336-341.

46 Veglia F, Vineis P, Overvad K, et al. Occupational exposures, environmental tobacco smoke, and lung cancer. Epidemiology 2007; 18: 769-775.

47 Künzli N, Perez L, Rapp R, eds. Air Quality and Health. Lausanne, European Respiratory Society, 2010.

48 European Commission. Survey on Tobacco: Analytical Report. Directorate General Communication, 2009. Available from: http://ec europa.eu/health/ph_determinants/life_style/Tobacco/Documents/ eb_253_en.pdf

49 World Health Organization. WHO Framework Convention Tobacco Control. www.who.int/fctc/en/index.html Date last updated: January 27, 2011.

50 Oberg M, Jaakkola MS, Woodward A, et al. Worldwide burden of disease from exposure to second-hand smoke: a retrospective analysis of data from 192 countries. Lancet 2011; 377: 139-146.

51 Hoogendoorn M, Feenstra TL, Hoogenveen RT, et al. Long-term effectiveness and cost-effectiveness of smoking cessation interventions in patients with COPD. Thorax 2010; 65: 711-718.

52 World Health Organization. Conference of the Parties to the WHO Framework Convention on Tobacco Control. Decisions. Geneva, World Health Organization, 2011. Available from: www.who.int/ fctc/copdecisions.pdf

53 Goodman P, Agnew M, McCaffrey M, et al. Effects of the Irish smoking ban on respiratory health of bar workers and air quality in Dublin pubs. Am J Respir Crit Care Med 2007; 175: 840-845.

54 Oberg M, Jaakkola M, Woodward A, et al. Worldwide burden of disease from exposure to second-hand smoke: a retrospective analysis of data from 192 countries. Lancet 2011; 377: 139-146.

55 Annesi-Maesano I, Forastiere F, Künzli N, et al. Particulate matter, science and EU policy. Eur Respir J 2007; 29: 428-431.

56 Pope CA III, Ezzati M, Dockery DW. Fine-particulate air pollution and life expectancy in the United States. N Engl J Med 2009; 360: 376-386.

57 Garcia-Aymerich J, Lange P, Benet M, et al. Regular physical activity modifies smoking-related lung function decline and reduces risk of chronic obstructive pulmonary disease: a population-based cohort study. Am J Respir Crit Care Med 2007; 175: 458-463.

58 Bourbeau J. Making pulmonary rehabilitation a success in COPD. Swiss Med Wkly 2010; 140: w13067.

59 van Wetering CR, Hoogendoorn M, Mol SJ, et al. Short- and longterm efficacy of a community-based COPD management programme in less advanced COPD: a randomised controlled trial Thorax 2010; 65: 7-13.

60 Haahtela T, von Hertzen L, Makela M, et al. Finnish Allergy Programme 2008-2018 - time to act and change the course. Allergy 2008; 63: 634-645.

61 Berghofer A, Pischon T, Reinhold T, et al. Obesity prevalence from a European perspective: a systematic review. BMC Public Health 2008; 8: 200

62 Peppard PE, Young T, Palta M, et al. Prospective study of the association between sleep-disordered breathing and hypertension. N Engl J Med 2000; 342: 1378-1384.

63 Marin JM, Carrizo SJ, Vicente E, et al. Long-term cardiovascular outcomes in men with obstructive sleep apnoea-hypopnoea with or without treatment with continuous positive airway pressure: an observational study. Lancet 2005; 365: 1046-1053.

64 The Definitive Guide to Lobbying the European Institutions. Brussels, Burson-Marsteller, 2005. 